\title{
Tau and $\beta$-Amyloid Are Associated with Medial Temporal Lobe Structure, Function, and Memory Encoding in Normal
} Aging

\author{
[DShawn M. Marks, ${ }^{1}$ @Samuel N. Lockhart, ${ }^{1}$ @Suzanne L. Baker, ${ }^{2}$ and $\oplus^{\oplus}$ William J. Jagust ${ }^{1,2}$ \\ ${ }^{1}$ Helen Wills Neuroscience Institute, University of California, Berkeley, California 94720, and ${ }^{2}$ Molecular Biophysics and Integrated Bioimaging, Lawrence \\ Berkeley National Laboratory, Berkeley, California 94720
}

\begin{abstract}
Normal aging is associated with a decline in episodic memory and also with aggregation of the $\beta$-amyloid $(\mathrm{A} \beta)$ and tau proteins and atrophy of medial temporal lobe (MTL) structures crucial to memory formation. Although some evidence suggests that $A \beta$ is associated with aberrant neural activity, the relationships among these two aggregated proteins, neural function, and brain structure are poorly understood. Using in vivo human $\mathrm{A} \beta$ and tau imaging, we demonstrate that increased $\mathrm{A} \beta$ and tau are both associated with aberrant fMRI activity in the MTL during memory encoding in cognitively normal older adults. This pathological neural activity was in turn associated with worse memory performance and atrophy within the MTL. A mediation analysis revealed that the relationship with regional atrophy was explained by MTL tau. These findings broaden the concept of cognitive aging to include evidence of Alzheimer's disease-related protein aggregation as an underlying mechanism of age-related memory impairment.
\end{abstract}

Key words: amyloid; episodic memory; fMRI; hippocampus; PET; tau

\section{Significance Statement}

Alterations in episodic memory and the accumulation of Alzheimer's pathology are common in cognitively normal older adults. However, evidence of pathological effects on episodic memory has largely been limited to $\beta$-amyloid $(\mathrm{A} \beta)$. Because $\mathrm{A} \beta$ and tau often cooccur in older adults, previous research offers an incomplete understanding of the relationship between pathology and episodic memory. With the recent development of in vivo tau PET radiotracers, we show that $\mathrm{A} \beta$ and tau are associated with different aspects of memory encoding, leading to aberrant neural activity that is behaviorally detrimental. In addition, our results provide evidence linking $\mathrm{A} \beta$ - and tau-associated neural dysfunction to brain atrophy.

\section{Introduction}

Successful episodic memory processes require a large-scale network of medial temporal lobe (MTL) structures, central to which are the hippocampus and entorhinal cortex. This network is highly susceptible to age-related decline, as evidenced by changes in cognition, structure, and function. Older adults often have difficulty forming new memories (Small et al., 1999; Hedden and

Received Dec. 8, 2016; revised Feb. 7, 2017; accepted Feb. 12, 2017.

Author contributions:S.M.M. and W.J.J. designed research;S.M.M. and S.L.B. performed research;S.M.M., S.N.L., and S.L.B. analyzed data; S.M.M., S.N.L., S.L.B., and W.J.J. wrote the paper.

This work was supported by the National Institutes of Health (Grant F31-AG049564 to S.M.M. and Grant R01AG034570 to W.J.J.). Avid Radiopharmaceuticals enabled use of the ${ }^{18} \mathrm{~F}-\mathrm{AV}-1451$ tracer but did not provide direct funding and were not involved in data analysis or interpretation. We thank Craig Stark for providing memory paradigm stimuli; Jim 0'Neil and Mustafa Janabi for PET radiotracer synthesis; and Kaitlin Swinnerton, Rachel Bell, and Taylor Mellinger for assistance with participant recruitment.

The authors declare no competing financial interests.

Correspondence should be addressed to Shawn M. Marks, Helen Wills Neuroscience Institute, 132 Barker Hall MC \#3190, University of California, Berkeley, CA 94720. E-mail: smmarks@berkeley.edu.

DOI:10.1523/JNEUROSCI.3769-16.2017

Copyright $\odot 2017$ the authors $\quad 0270-6474 / 17 / 373192-10 \$ 15.00 / 0$
Gabrieli, 2004) and neuroimaging studies have repeatedly found that MTL volumes decrease across the lifespan (Jernigan et al., 1991; Pruessner et al., 2001; Raz et al., 2004). The structures leveraged by the episodic memory network are also disrupted in Alzheimer's disease (AD). The formation of tau neurofibrillary tangles is first seen in the transentorhinal and entorhinal cortex (Braak and Braak, 1991, 1997), whereas $\beta$-amyloid (A $\beta$ ) plaques accumulate in a number of neocortical regions that are ultimately reciprocally connected to the hippocampus via the entorhinal cortex and perforant pathway (Braak and Braak, 1991; Thal et al., 2002). In conjunction with these two aggregated proteins, atrophy of the hippocampus and entorhinal cortex are hallmarks of the disease (Laakso et al., 1996; Scheltens, 2001).

Recent fMRI studies of age-related memory decline have demonstrated that hippocampal hyperactivity is often observed in older adults compared with young controls (Miller et al., 2008; Yassa et al., 2011). Because AD pathology is commonly observed in cognitively normal individuals (Bennett et al., 2006), some degree of what is considered as normal age-related decline may be 
attributable to $\mathrm{AD}$ pathology. In fact, multiple studies have reported alterations in the hippocampal memory network that are associated with $\mathrm{A} \beta$. Elevated $\mathrm{A} \beta$ has been linked to increased hippocampal activation (Mormino et al., 2012), increased entorhinal cortex activation (Huijbers et al., 2014), and reduced taskinduced deactivation (Sperling et al., 2009) in cognitively normal older adults. $A \beta$ is thought to be excitotoxic, potentially leading to aberrant cellular activity (Mattson et al., 1992; Busche et al., 2008); however, $A \beta$ is unlikely to be the sole contributor to memory impairment. Tau is more closely associated with $\mathrm{AD}$ symptoms than is A $\beta$ (Arriagada et al., 1992; van Rossum et al., 2012) and, whereas MTL tau pathology is common as an isolated pathology in older people (Crary et al., 2014), A $\beta$ often cooccurs with tau pathology (Price and Morris, 1999; Chabrier et al., 2012) and may be involved in its spread to neocortex (Schöll et al., 2016). Neuroimaging studies to date have been limited in that they do not fully account for the role of both $A \beta$ and tau in relation to MTL function.

To examine the effect of AD pathology on memory network function and decline in normal aging, we used a lure discrimination paradigm specifically designed to tax the hippocampal formation. A core function of the hippocampus is to orthogonalize information into noncompeting representations or pattern separation (Marr, 1971; Treves and Rolls, 1994; O'Reilly and Norman, 2002). However, older adults, when confronted with stimuli that are similar but not identical to those previously observed, frequently misidentify these lures as older representations (pattern completion). This age-related behavioral change has been associated with both increased hippocampal activation and structural degradation of the perforant pathway and limbic tracts, potentially disconnecting hippocampus from neocortex (Yassa et al., 2010a, 2011; Bennett et al., 2015). Because tau accumulation in cognitively normal older adults usually occurs in the entorhinal cortex and hippocampus (Braak and Braak, 1997), a reasonable hypothesis is that tau accumulation provokes hippocampal dysfunction and produces memory impairment in aging. In addition, our previous work, as well as other work cited above, implicates $A \beta$ involvement in hippocampal hyperactivation. Therefore, our goal was to explore relationships between tau and $\mathrm{A} \beta$ accumulation, measured with ${ }^{18} \mathrm{~F}-\mathrm{AV}-1451$ (Xia et al., 2013) and ${ }^{11}$ C-Pittsburgh compound B (PIB; Price et al., 2005) PET, to task-related brain activation, episodic memory, and brain structure in cognitively normal older adults. We hypothesized that increased task-related activation would be associated with impaired cognitive performance, atrophy of the MTL, and both tau and A $\beta$.

\section{Materials and Methods}

Participants. Sixty healthy older adults (OA) aged 64-93 years (40 female) and 24 young adults (YA) aged 18-30 years (16 female) were recruited from the Berkeley Aging Cohort, an ongoing longitudinal study of cognitive aging, to participate in PET and MRI imaging. All participants underwent a detailed medical interview and a battery of neuropsychological assessments before enrollment. To be eligible, OA were required to be 64 years of age or older, living independently in the community, free of neurological and major medical illness, and have normal performance on neuropsychological tests (within $1.5 \mathrm{SD}$ of the mean). Seventeen OA and 4 YA were excluded because of poor performance (below chance on lure discrimination, $n=2$ ), problems with data collection (behavioral and MRI, $n=8)$ or image normalization $(n=3)$, and excessive motion $(n=8)$, resulting in $43 \mathrm{OA}$ and 20 YA for subsequent data analysis (Table 1). All OA received MRI and ${ }^{11} \mathrm{C}$-PIB PET for amyloid imaging and a subset received ${ }^{18} \mathrm{~F}-\mathrm{AV}-1451$ PET $(n=35)$ for tau imaging. YA only participated in MRI imaging. MRI scans were acquired
Table 1. Participant demographics

\begin{tabular}{lll}
\hline & YA & OA \\
\hline$n$ & 20 & 43 \\
Age & $23.25(3.21)$ & $78.80(5.75)$ \\
Sex (M/F) & $7 / 13$ & $12 / 31$ \\
Education & $15.21(1.58)^{a}$ & $16.63(1.98)$ \\
MMSE & $29.00(1.26)$ & $28.86(1.21)$ \\
APOE (0/1/2 \&4 allele) & N/A & $28 / 14 / 0(1 \mathrm{~N} / \mathrm{A})$ \\
PIB DVR & $\mathrm{N} / \mathrm{A}$ & $1.12(0.18)$ \\
AV-1451 SUVR (Braak I/II) & $\mathrm{N} / \mathrm{A}$ & $1.51(0.19)$ \\
Days between MRI and PIB & $\mathrm{N} / \mathrm{A}$ & $97.58(94.81)$ \\
Days between MRI and AV-1451 & $\mathrm{N} / \mathrm{A}$ & $123.66(198.97)$ \\
\hline
\end{tabular}

All values are mean (SD) unless stated otherwise.

MMSE, Mini-Mental State Examination; APOE, Apolipoprotein E.

aSignificantly different from OAs (two-sample $t$ test, $p<0.05$ ).

within an average of $97.58 \pm 94.81 \mathrm{~d}$ from PIB and $123.66 \pm 198.97 \mathrm{~d}$ from AV-1451 PET scans. All participants provided informed consent in accordance with the Institutional Review Boards of the University of California, Berkeley, and the Lawrence Berkeley National Laboratory (LBNL).

Behavioral task. The episodic memory paradigm used was adapted from Yassa et al. (2011). Across six runs in the scanner, participants were shown color photographs of novel, repeated, and similar (i.e., lure) objects. Participants were told to identify the objects seen as new (first), old (repeat), or similar but not identical (lure). Objects were presented one at a time for $2000 \mathrm{~ms}$, followed by a black fixation cross with a fixed $500 \mathrm{~ms}$ intertrial interval. Each run contained 16 repeated pairs, 16 lure pairs, and 44 novel objects, with no objects duplicated between runs. Objects were fully randomized and the distance between repeated and lure pairs was randomly varied between 10 and 40 trials. PsychoPy (RRID: SCR_006571) was used for stimulus presentation and behavioral data collection.

PET acquisition. PIB was synthesized at the LBNL Biomedical Isotope Facility. PIB-PET imaging was performed at LBNL using an ECAT EXACT HR or BIOGRAPH PET/CT Truepoint 6 scanner (Siemens Medical Systems) in 3D acquisition mode. Thirty-five dynamic acquisition frames were obtained over $90 \min (4 \times 15 \mathrm{~s}, 8 \times 30 \mathrm{~s}, 9 \times 60 \mathrm{~s}, 2 \times 180 \mathrm{~s}$, $10 \times 300 \mathrm{~s}$, and $2 \times 600 \mathrm{~s}$ ) immediately after injection of $10-15 \mathrm{mCi}$ of PIB into an antecubital vein. Ten-minute transmission scans for attenuation correction or $\mathrm{x}$-ray CT were obtained for each PIB scan. Data were reconstructed using an ordered subset expectation maximization algorithm with weighted attenuation and smoothed with a $4 \mathrm{~mm}$ Gaussian kernel with scatter correction.

AV-1451 was synthesized at LBNL using a GE TracerLab FXN-Pro synthesis module with a modified protocol based on that supplied by Avid Radiopharmaceuticals. AV-1451 PET imaging was performed on the BIOGRAPH PET/CT scanner. After the injection of $10 \mathrm{mCi}$ of AV1451, 1 of 2 acquisition schemes were acquired: $0-100 \mathrm{~min}$ of dynamic data $(4 \times 15 \mathrm{~s}, 8 \times 30 \mathrm{~s}, 9 \times 60 \mathrm{~s}, 2 \times 180 \mathrm{~s}$, and $16 \times 300 \mathrm{~s}$ frames $)$, followed by $120-150 \mathrm{~min}(6 \times 300 \mathrm{~s}$ frames, $n=18)$ or $75-115 \mathrm{~min}(8 \times$ $300 \mathrm{~s}$ frames, $n=17)$. Analyzed data from both acquisition schemes used only frames from $80-100 \mathrm{~min}$. A CT scan was performed before the start of each emission acquisition. Data were reconstructed using an ordered subset expectation maximization algorithm with weighted attenuation and smoothed with a $4 \mathrm{~mm}$ Gaussian kernel with scatter correction.

MRI acquisition. High-resolution $\mathrm{fMRI}$ was performed at the Henry $\mathrm{H}$. Wheeler Jr. Brain Imaging Center (BIC) on a 3T TIM/Trio scanner (Siemens Medical Systems) using a 32-channel head coil. Each of the six functional runs used a $\mathrm{T} 2^{\star}$-weighted echoplanar imaging sequence $\left(\mathrm{TR}=1500 \mathrm{~ms} ; \mathrm{TE}=34 \mathrm{~ms} ;\right.$ flip angle $=70^{\circ} ;$ matrix $=132 \times 132 ;$ FOV $=200$; voxel size $=1.5 \times 1.5 \times 1.5 \mathrm{~mm}$; duration $=5 \mathrm{~min})$. A parallel imaging reduction factor of 2 was used to reduce acquisition time and minimize distortion due to magnetic susceptibilities near the temporal lobes. Nineteen slices oriented parallel to the primary axis of the hippocampus were acquired in interleaved order, covering the entirety of the MTL. A total of 196 volumes were acquired during each run. The first 10 volumes were discarded because they were used to ensure signal equi- 
librium and minimal subject motion during the parallel imaging normalization template acquisition. A T1-weighted volumetric magnetization prepared rapid gradient echo image (MPRAGE; TR $=2300 \mathrm{~ms}$; $\mathrm{TE}=2.98 \mathrm{~ms}$; matrix $=256 \times 256 ; \mathrm{FOV}=256$; sagittal plane; voxel size $=1 \times 1 \times 1 \mathrm{~mm}$; 160 slices) was collected and used during coregistration of functional data. An MPRAGE image $(\mathrm{TR}=2110 \mathrm{~ms}$; $\mathrm{TE}=$ $3.58 \mathrm{~ms}$; matrix $=256 \times 256$; FOV $=256$; sagittal plane; voxel size $=1 \times$ $1 \times 1 \mathrm{~mm}$; 160 slices) was also collected at LBNL on a 1.5T Magnetom Avanto (Siemens Medical Systems) for PET coregistration purposes.

PET processing. PET data were processed using the SPM12 software package (RRID:SCR_007037). PIB-PET data were realigned and frames corresponding to the first $20 \mathrm{~min}$ of acquisition were averaged and used to guide coregistration with the participant's LBNL MPRAGE. The coregistration matrix was applied to realigned frames and data were resliced to MRI space. Distribution volume ratio (DVR) images of PIBPET data 35-90 min after injection were created using Logan graphical analysis and a FreeSurfer-derived gray cerebellum reference region (Logan, 2000). Global PIB DVR values were calculated for each participant, defined as the mean DVR within regions of interest (ROIs) in the frontal, parietal, temporal, and cingulate cortices (Mormino et al., 2011). Previous work demonstrated that global PIB DVR values did not differ significantly between the two scanners used for data collection (Elman et al., 2014).

AV-1451-PET data were realigned and the mean of all frames was used to coregister data to the participant's LBNL MPRAGE. Standard uptake value (SUV) images representing data 80-100 min after injection were created and normalized by a gray cerebellum reference region to generate native space SUV ratio (SUVR) images. SUVR images were partial volume corrected using the Rousset approach (Rousset et al., 1998). Volume-weighted mean SUVR values within anatomically approximated Braak staging were calculated using a method described previously (Schöll et al., 2016). Briefly, Braak ROIs were created by combining FreeSurfer segmentations (see below) into nonoverlapping stages used to describe $\mathrm{AD}$-related tau pathology (i.e., I/II transentorhinal, III/IV limbic, and V/VI isocortical).

MRI processing. BIC and LBNL MPRAGE data were processed using FreeSurfer version 5.3 (RRID:SCR_001847) to define native space ROIs for each participant (Dale et al., 1999; Fischl et al., 2001, 2002; Ségonne et al., 2004). FreeSurfer ROIs obtained using LBNL data were used to create Braak ROIs and to calculate PIB DVR values. FreeSurfer ROIs obtained using BIC data were used to measure thickness of MTL subregions, averaged across hemispheres. Hippocampus and entorhinal, parahippocampal, and perirhinal cortices were segmented manually for each participant on BIC MPRAGE images following previously established guidelines (Insausti et al., 1998; Pruessner et al., 2002; Duvernoy, 2005). These segmentations were used to quantify average hippocampal volume. Hippocampal volume was corrected for total intracranial volume (ICV) using a covariance approach, as defined by the following formula: adjusted volume $=$ raw volume $-\beta^{*}(\mathrm{ICV}-$ mean ICV $)$, with $\beta$ being the regression coefficient when raw volume is regressed against ICV and mean ICV being the group average (Mathalon et al., 1993).

fMRI processing. fMRI data were processed and analyzed using a combination of Advanced Normalization Tools (RRID:SCR_004757) and SPM12. For a given run, images were realigned to the first volume and smoothed with a $5 \mathrm{~mm}$ Gaussian kernel. Motion vectors were created and used to identify significant motion spikes ( $>2 \mathrm{~mm}$ displacement \pm 1 TR). A mean fMRI image was created, bias corrected, and thresholded to exclude surrounding nonbrain tissue and skull. The resulting image was used in a two-step spatial normalization process. First, the mean fMRI image was linearly registered to the participant's skull-stripped BIC MPRAGE. Second, the BIC MPRAGE was nonlinearly registered to the skull-stripped MNI ICBM 152 Nonlinear Asymmetric template (Fonov et al., 2009). The two transformations were combined and applied to the participant's fMRI data as one transformation.

fMRI analysis. Individual runs were modeled using FSL's FEAT version 6.0 (RRID:SCR_002823). Trials were categorized into eight bins. Four of these represented activity upon the first presentation of the stimuli: (1) novel objects (stimuli presented only once), (2) subsequent hits $(\mathrm{sH}),(3)$ subsequent correct rejections (sCR), and (4) subsequent false alarms (sFA). Three represented activity upon presentation of the paired stimuli: (5) hits (repeat presentation correctly identified as old), (6) correct rejections (lure presentations correctly identified as similar), and (7) false alarms (lure presentations incorrectly identified as old), with an eighth category of errors and omissions. Data were convolved with a double-gamma hemodynamic response function and each bin, their corresponding temporal derivatives, six rigid body motion parameters, and outlier volumes (those with excessive motion) were entered in a general linear model to predict fMRI signal. The resulting contrasts reflect activity for a given task-related bin relative to the nonzero, novel object baseline condition. Second-level contrasts were created for each participant by combining all six runs using a one-sample $t$ test with fixed effects. Third-level group statistics were created for all $\mathrm{sH}$, $\mathrm{sCR}$, and sFA by combining all individual subject data using one-sample $t$ tests. All third-level statistics were masked to only include hippocampus and the entorhinal, parahippocampal, and perirhinal cortices $(98,2561.5$ $\mathrm{mm}^{3}$ voxels) as defined above; a threshold of $p<0.05$ uncorrected and $k \geq 250$ cluster extent was used. Each condition's significant activations or deactivations were binarized and used to extract data from individual participants. Differences between groups were quantified using twosample $t$ tests.

Statistical analyses. Statistical analyses and plots were performed using R version 3.2.3 (RRID:SCR_001905). Group differences were assessed using $t$ tests. Multiple regression was used to assess relationships among cognition, task activation, and biomarker data within OAs. All regression analyses were controlled for age, sex, and education. Regression models involving PET biomarkers were additionally controlled for hippocampal volume to account for spatial resolution differences between highresolution $\mathrm{fMRI}$ and PET. Mediation analyses were performed using the "mediation" package in R. Dice's coefficient was calculated to quantify the similarity between clusters of task-related activation. Significant relationships were reported at $p<0.05$ and trends of $p<0.1$ were addressed.

\section{Results}

\section{Memory performance}

All participants were administered the memory paradigm outlined in Figure $1 A$ during fMRI data acquisition. Differences were found between OA and YA for all but one behavioral condition, repeated objects called new, with the most pronounced differences seen for lure objects called similar (Fig. 1B). To assess task performance, a lure discrimination index (LDI) was defined as $(p[$ similar|lure $]+p[$ new $\mid$ lure $])-p$ (similar|first $)$. This measure generally describes the likelihood that a lure was correctly identified and corrects for response bias within participants. Overall, OA performed worse compared with YA $\left(t_{(52)}=-5.70, p<\right.$ 0.001; Fig. 1C).

\section{Activation and deactivation patterns in older adults}

Neural activity during stimulus encoding for three conditions was compared with activity for novel stimuli presented only once using one-sample $t$ tests in the OA group (Fig. 2). Activations associated with $\mathrm{sH}$ (correctly identified as old on the subsequent presentation) were found in left entorhinal cortex and bilateral parahippocampal cortex. Clusters of $\mathrm{sH}$ deactivations were found in left perirhinal cortex near the border of the entorhinal cortex, bilateral anterior hippocampus, and right posterior hippocampus. For sCR (correctly identified as similar on the subsequent presentation), activations were found in bilateral perirhinal cortex, left anterior hippocampus, left posterior hippocampus, and right parahippocampal cortex. No clusters of voxels exceeded the threshold for deactivations. sFA (subsequently incorrectly identified as old upon presentation of a lure) activations were found in bilateral perirhinal cortex, left anterior hippocampus, left posterior hippocampus, left parahippocampal cortex, and right entorhinal cortex. sFA deactivations were 
A

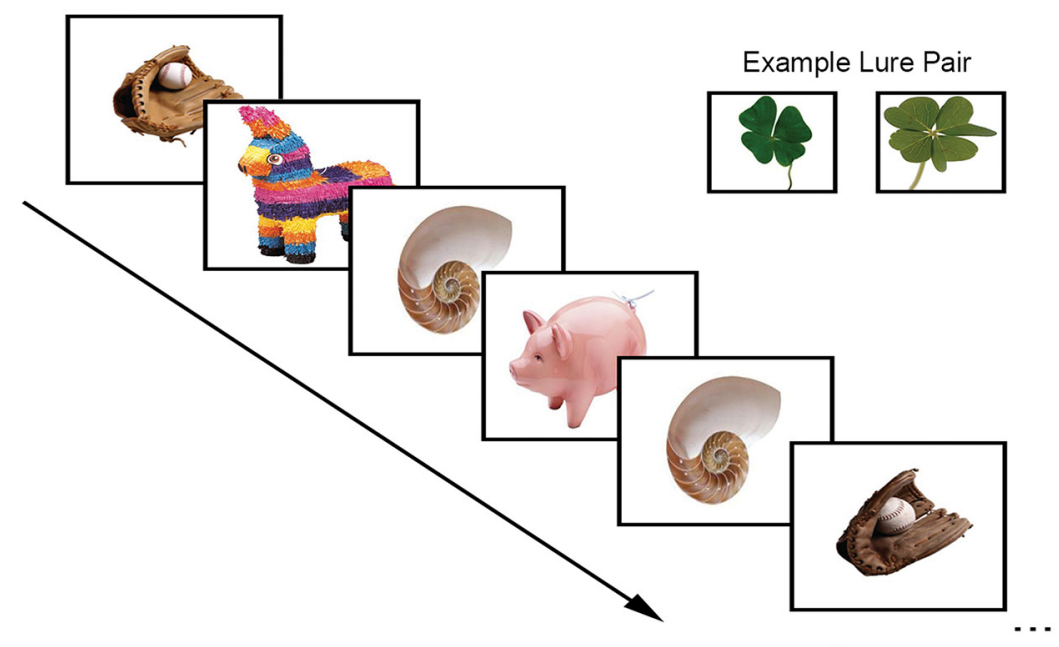

B

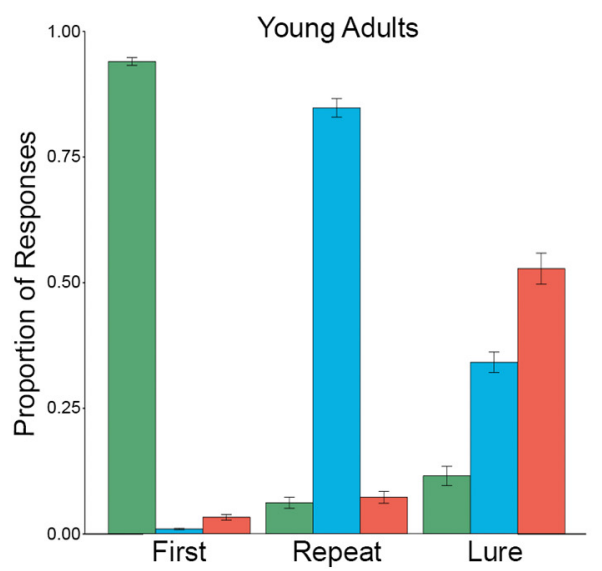

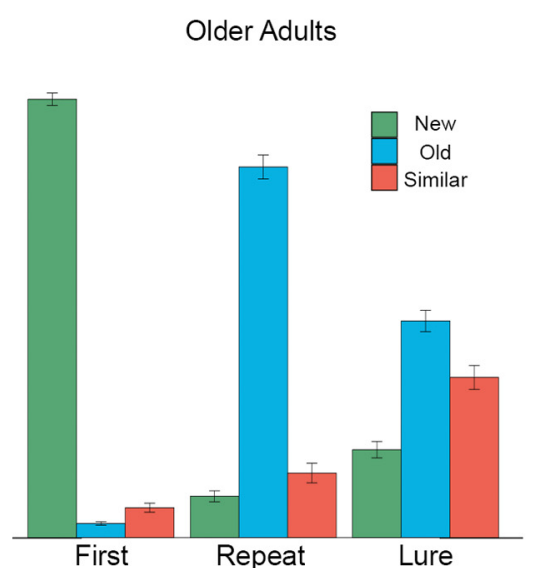

C

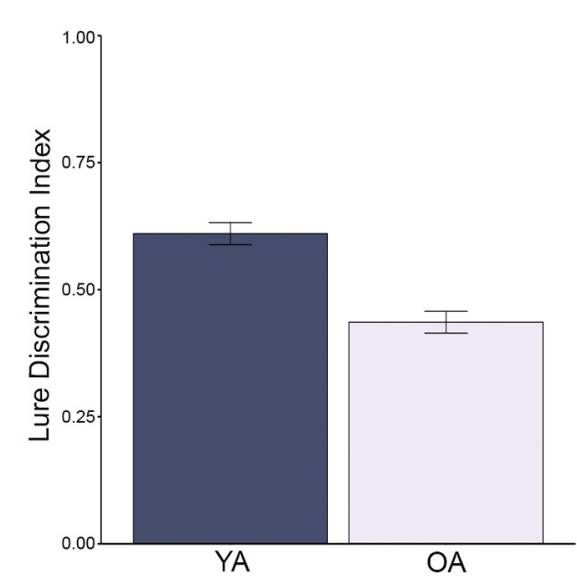

Figure 1. Lure discrimination paradigm and behavioral performance. A, Participants were instructed to identify objects as being new (first presentation of object), old (repeated object), or similar (lure object resembling a previous trial). Objects were presented for $2000 \mathrm{~ms}$, followed by a $500 \mathrm{~ms}$ intertrial interval. Similar lures acted as the primary trials for assessing memory performance. $B$, Proportion of response for each trial type. Responses to all trial types differed between YA and OA, with OA generally performing worse. C, LDI, quantifying the likelihood of correctly identifying lure objects, was significantly lower for $0 \mathrm{~A}$ compared with YA. Data presented as means $\pm \mathrm{SE}$.

found in right entorhinal cortex and right anterior and posterior hippocampus.

\section{Differences in activation and deactivation patterns between older and young adults}

To determine whether neural activity differed between the OA and YA groups, we first quantified activity in YA within the contrasts identified using one-sample $t$ tests of OA. Compared with $\mathrm{OA}$, YA had significantly reduced activation in the $\mathrm{sH}\left(t_{(43)}=\right.$ $-2.58, p=0.01)$ and sFA $\left(t_{(54)}=-3.64, p<0.001\right)$ contrasts. A nonsignificant trend was observed in the sCR contrast $\left(t_{(30)}=\right.$ $-1.88, p=0.07)$. In addition, we performed two-sample $t$ tests to explore explicit differences between groups (Fig. 3). Numerous clusters of increased activation were found in OA for all trial types. Specifically, clusters were found in right anterior hippocampus, bilateral entorhinal and bilateral parahippocampal cortex for $\mathrm{sH}$; bilateral hippocampus (both anterior and posterior) and right parahippocampal cortex for sCR; and right entorhinal cortex, bilateral anterior hippocampus, and bilateral parahippocampal cortex for sFA. Only one cluster of activity in left anterior hippocampus was associated with increased activity in YA during sH trials. Finally, we sought to compare patterns of activation derived from both analyses by calculating Dice's coef- ficient for each trial type. Values associated with $\mathrm{sH}$, sCR, and sFA activations were calculated to be $0.28,0.10$, and 0.45 , respectively. Although these values indicate that the two analyses do not completely overlap, there is likely shared neural activity between groups that may not arise using $t$ tests, but is required to perform lure discrimination. Therefore, we chose to assess further relationships with task-related activation using the contrasts defined within OA only.

\section{Amyloid and tau characteristics in older adults}

Approximately $45 \%$ of OA were classified as $\mathrm{A} \beta+$ using a cutoff of 1.07, which has been detailed previously (Villeneuve et al., 2015). This percentage is higher than most studies of cognitively normal older adults because the participants were recruited to enrich for $\mathrm{A} \beta$ to better test our hypotheses. Tau was quantified into three measures that closely approximated anatomically defined Braak staging. Specifically, Braak I/II contained entorhinal cortex and hippocampus; Braak III/IV contained limbic structures including inferior temporal cortex, amygdala, and thalamus; and Braak V/VI contained isocortical structures including the frontal, parietal, and occipital cortices. Of the 35 total participants included in analyses, $6 \mathrm{OA}$ were classified as Braak 0, $23 \mathrm{OA}$ were classified as Braak I/II, and 6 OA were classified as Braak 


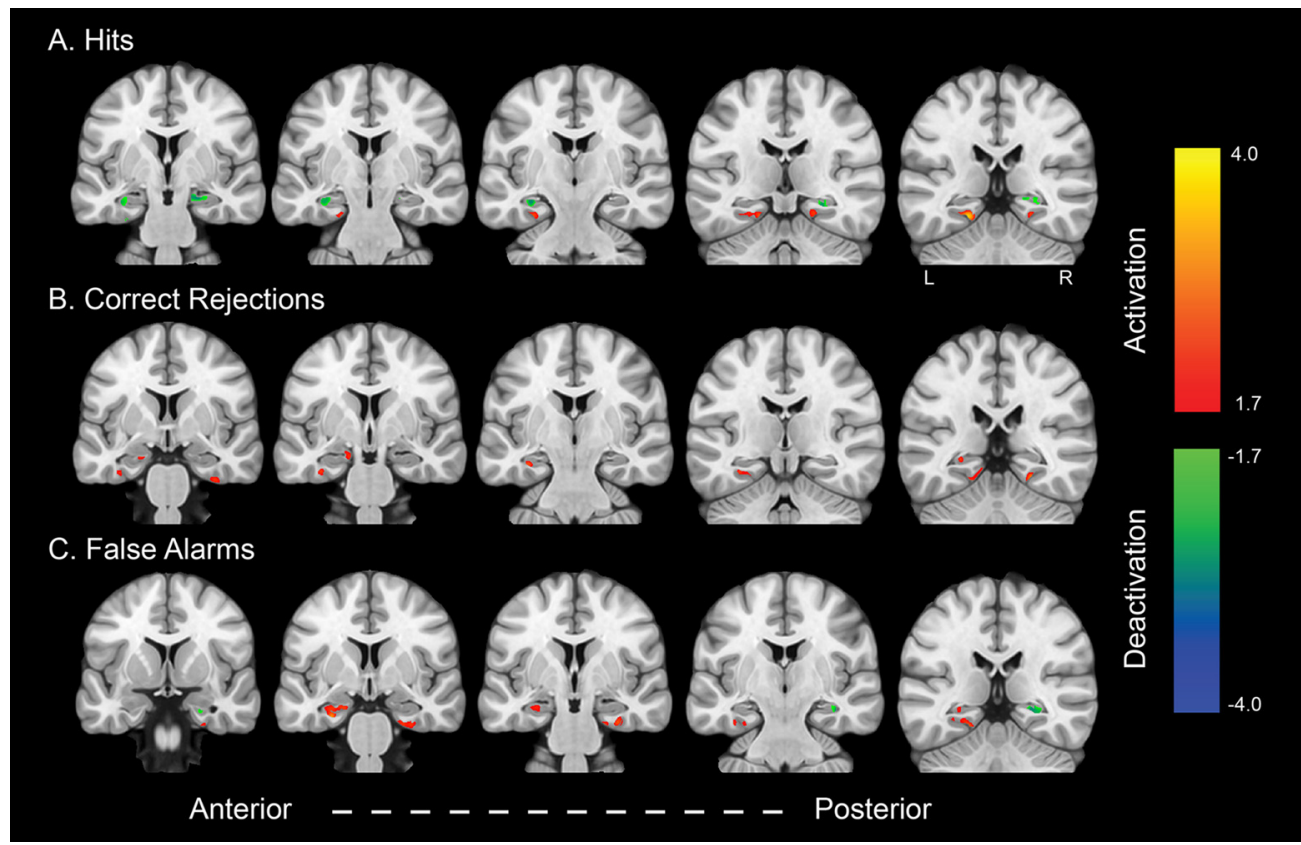

Figure 2. Patterns of fMRl activation during memory encoding in $0 \mathrm{~A}$. Shown are one-sample tests of activation (shown in warm colors) and deactivation (shown in cool colors) in $0 \mathrm{~A}$ during trials of $\mathrm{SH}(\boldsymbol{A}), \mathrm{SCR}(\boldsymbol{B})$, and SFA $(\boldsymbol{C})$ compared with novel stimuli presented only once. Data are presented as t statistics.

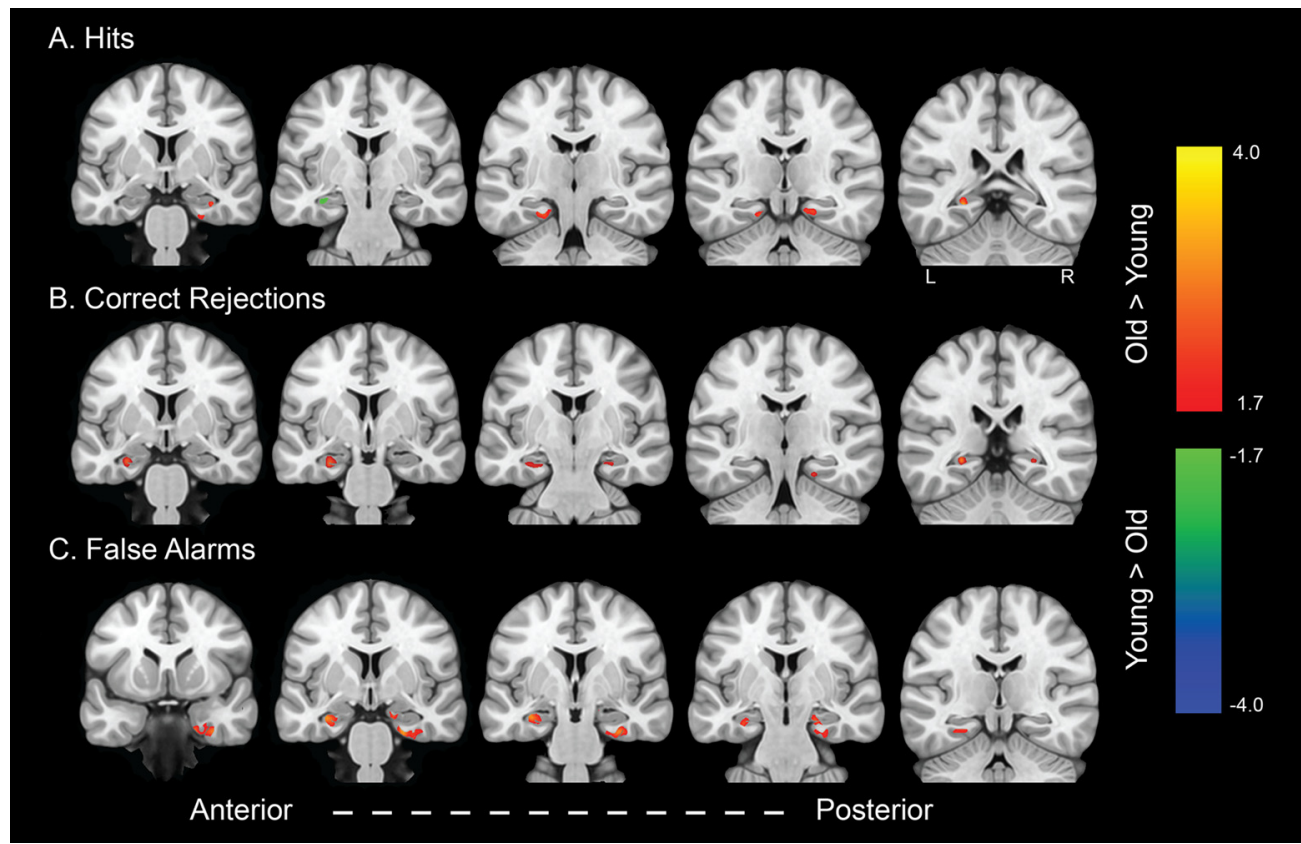

Figure 3. Differences in fMRI activation during memory encoding between $O A$ and $Y A$. Patterns of activation associated with group difference between $O A$ (warm colors) and $Y A$ (cool colors) during trials of $\mathrm{sH}(\boldsymbol{A}), \mathrm{sCR}(\boldsymbol{B})$, and $\mathrm{SFA}(\boldsymbol{C})$. Data are presented as $t$ statistics.

III/IV. No OA had substantial tau in Braak V/VI regions. Because the majority of OA had tau deposition in the Braak I/II regions, the other stages were excluded from further analyses. Age was significantly associated with Braak I/II tau such that older participants had more tau $\left(r_{(33)}=0.48, p=0.002\right)$. Representative PIB and AV-1451 images are shown in Figure 4.

Relationships with task-specific activation

To determine whether early $\mathrm{AD}$ pathology influences brain function during memory encoding, we sought to relate measures of tau and $\mathrm{A} \beta$ pathology with task-related activation. No signifi- cant relationships were found with $\mathrm{sCR}$ activations. Reduced $\mathrm{sH}$ deactivations were associated with increased global PIB DVR $\left(r_{(36)}=0.47, p=0.05\right.$; Fig. $\left.5 A\right)$, with females deactivating more than males $\left(t_{(28)}=-2.77, p=0.01\right)$. Increased activations during sFA were associated with elevated tau in Braak I/II $\left(r_{(28)}=0.41\right.$, $p=0.01$; Fig. $5 B$ ). The results would not survive a Bonferroniadjusted $p$-value of 0.005 .

Although older participants showed greater activation than younger for all three task conditions, we chose to examine pathological effects (as opposed to age-related effects) by combining neural measures that were uniquely susceptible to $A \beta$ and tau. Therefore, 


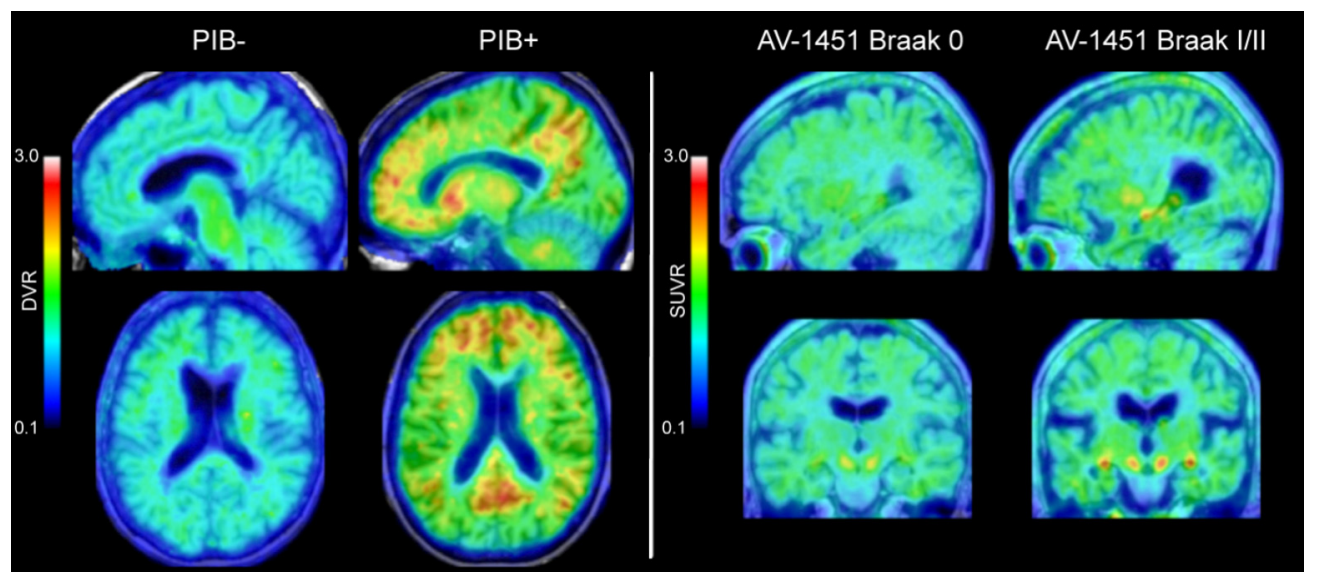

Figure 4. PIB and AV-1451 PET imaging. DVR and SUVR images of PIB and AV-1451 binding in representative participants are shown. Areas of significant A $\beta$ burden were seen in frontal and parietal cortices and posterior cingulate. Significant tau burden was largely restricted to the MTL.
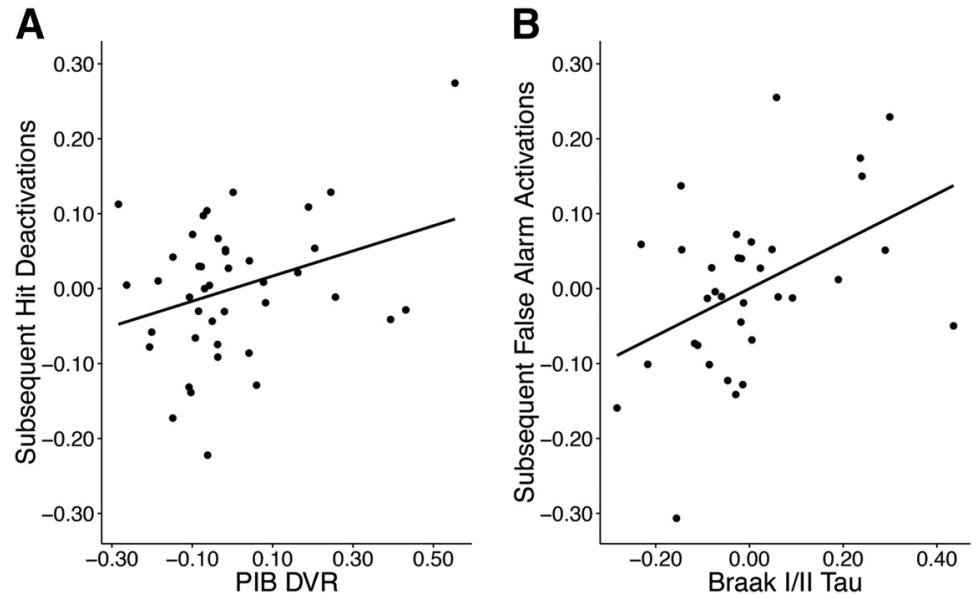

Figure 5. Relationship between $f M R I$ activation and AD pathology. $A$, Positive relationship between PIB DVR (measure of $A \beta$ ) and sH deactivations $\left(r_{(36)}=0.47, p=0.05\right)$. B, Positive relationship between AV-1451 Braak I/II SUVR (measure of tau) and sFA activations $\left(r_{(28)}=0.41, p=0.01\right)$. Data are residuals controlling for age, sex, education, and hippocampal volume.

we generated a pathological activation composite measure by combining $z$-transformed data for $\mathrm{sH}$ deactivations and $\mathrm{sFA}$ activations. To determine whether elevated pathological activation was detrimental to memory, average activation from the composite measure was related to the LDI. There was a significant relationship with LDI such that OA with increased pathological activation performed worse on the memory paradigm $\left(r_{(38)}=0.35, p=0.05\right.$, Fig. $\left.6 A\right)$. Based on extensive data linking AD pathology to MTL brain structure, we sought to explore whether hippocampal volume and the thickness of surrounding cortical regions were also associated with pathological activation. Thinner average entorhinal cortex $\left(r_{(38)}=\right.$ $0.44, p=0.007$; Fig. $6 B)$, as well as marginally smaller hippocampal volume $\left(r_{(37)}=0.34, p=0.07\right)$, was associated with increased pathological activation in OA. The relationship with entorhinal thickness survived a Bonferroni-adjusted $p$-value of 0.01 . Older age was additionally associated with thinner entorhinal cortex $\left(r_{(41)}=0.39, p=\right.$ $0.006)$ and smaller hippocampal volume $\left(r_{(40)}=0.29, p=0.04\right)$.

Relationships between pathology, cortical thickness, and pathological activation

We sought to better understand the relationship between MTL structure, $\mathrm{AD}$ pathology, and pathological activation; therefore, we performed a mediation analysis to better define the relationships between MTL tau, pathological activation, and average entorhinal cortical thickness, as depicted in Figure 7. First, the total effect of pathological activation correlating with entorhinal thickness was significant in the OA with tau imaging ( $\beta=-0.09, p=0.02)$. Second, as expected, pathological activation was significantly associated with Braak I/II tau $(\beta=$ $0.05, p=0.02$ ). Third, Braak I/II tau was significantly correlated with entorhinal thickness $(\beta=-0.67, p=0.03)$. Fourth, pathological activation was no longer associated with entorhinal thickness when controlling for Braak I/II tau $(\beta=-0.05, \mathrm{NS})$. The indirect effect was tested using a Monte Carlo simulation with 5000 simulations. The effect was measured to be -0.03 with $95 \%$ confidence intervals of -0.08 to -0.002 , indicating that the indirect effect was significant. Increased pathological activation was associated with a 0.03 decrease in entorhinal thickness as mediated by Braak I/II tau pathology. A secondary analysis assessing whether $\mathrm{A} \beta$ also mediated the relationship between pathological activation and entorhinal cortical thickness was not significant.

\section{Discussion}

The presence of $\mathrm{AD}$ pathology in cognitively normal older adults may contribute to the disruption of memory function commonly observed in aging. This study explored the relationship among cognition, MTL memory network structure and function, and in vivo measures of tau and $\mathrm{A} \beta$. We confirmed previous reports that older adults exhibit impaired lure discrimination ability, reflecting a bias toward pattern completion. We also found that tau and $\mathrm{A} \beta$ pathology are related to two different components of memory encoding, hits and false alarms, which we combined to describe a disruption in network function. The combined pathological activation measure was associated with both worse memory and atrophy of the MTL. Furthermore, a mediation analysis revealed that tau in the hippocampus and entorhinal cortex explained the relationship between pathological activation and cortical thickness. These results suggest that the cooccurrence of tau and $\mathrm{A} \beta$ 
plays a critical role in the development of age-related memory decline, particularly by leading to aberrant activity throughout the hippocampal memory network and to atrophy of crucial brain structures.

\section{Task activation in older adult cohorts} Increased task-induced activation has been a frequent finding in cognitively normal older adults and individuals with mild cognitive impairment (MCI). Multiple studies have reported hippocampal hyperactivity during episodic memory (Miller et al., 2008; Yassa et al., 2010b, 2011), which may be interpreted as aberrant due to its frequent negative association with memory performance. Using the same lure discrimination paradigm, Bakker et al. (2012) reported increased hippocampal activation in amnestic MCI subjects in relation to cognitively normal older adults that was negatively associated with task performance. Although our results and numerous aging studies have reported increased hippocampal activation, others have reported decreased activation (Cabeza et al., 2004; Dennis et al., 2008) or no difference in activation (Sperling et al., 2003; Duverne et al., 2009) compared with young controls. These disparate findings are likely related to differences in task and task difficulty, varied subject demographics, and the uncertain pathological status of participants.

\section{Task activation as a function of Alzheimer's pathology}

Our results are in agreement with existing literature indicating that measurement of pathological proteins explains increased activation during memory encoding above the effects of chronological age. Specifically, several studies have linked elevated $\mathrm{A} \beta$ to altered brain function during episodic memory (Sperling et al., 2009; Mormino et al., 2012; Vannini et al., 2012; Elman et al., 2014; Huijbers et al., 2015). Mormino et al. (2012) reported increased hippocampal activation in cognitively normal older adults with significant $\mathrm{A} \beta$ burden, whereas Sperling et al. (2009) demonstrated that reduced task-induced deactivations were associated with elevated $\mathrm{A} \beta$ deposition. A recent study reported an association between increased $\mathrm{A} \beta$ and decreased task activation, but the hippocampus and broader MTL were not implicated (Kennedy et al., 2012). Animal models of AD have suggested that $\mathrm{A} \beta$-related increased neural activity is epileptiform in nature $(\mathrm{Pa}-$ lop et al., 2007) and is associated with the deposition of $\mathrm{A} \beta$ (Cirrito et al., 2005; Bero et al., 2011), potentially leading to a vicious cycle. Human neuroimaging data demonstrating that the antiepileptic drug levetiracetam both reduced hippocampal activity and improved memory support this interpretation (Bakker et al., 2012).

However, some studies have suggested that increased neural activity may play a compensatory role (Miller et al., 2008). We previously reported that increased activity in parietal and occipital cortex, but not hippocampus, was associated with better memory performance in $\mathrm{A} \beta+$ individuals (Elman et al., 2014). Differences in interpretation may depend to some extent on which brain regions are examined. For example, aberrant hippocampal activity may better reflect pathological changes, whereas activation outside of the MTL might be indicative of other processes. Regardless of the precise cause, accumulating

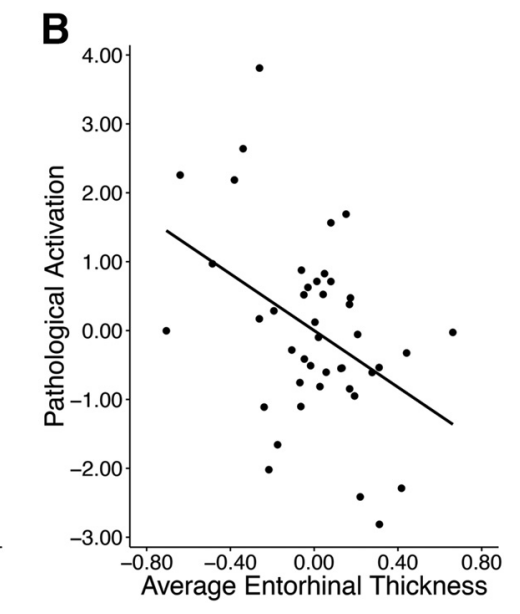

ure Discrimination Index nemory, and cortical thickness. $\boldsymbol{A}$, Negative relationship
sH deactivations and sFA activations) and lure discrimination between pathological activation (as defined by combining $\mathrm{SH}$ deactivations and sFA activations) and lure discrimination
index $\left(r_{(38)}=0.35, p=0.05\right)$. $\boldsymbol{B}$. Negative relationship between pathological activation and average entorhinal cortex thickness $\left(r_{(38)}=0.44, p=0.007\right)$. Data are residuals controlling for age, sex, and education.

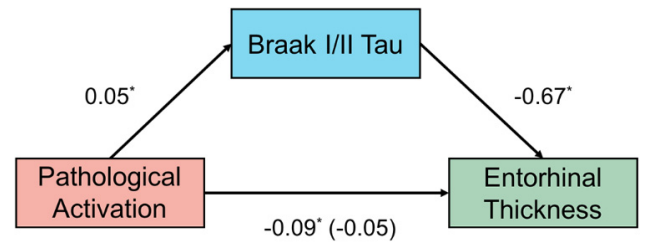

Figure 7. Mediation analysis of pathological activation, Braak I/II tau, and cortical thickness Mediation analysis with pathological activation (red), mediated by Braak I/II AV-1451 standard uptake volume ratio (blue), predicting right entorhinal cortical thickness (green) are shown. Pathological activation positively predicted Braak I/II AV-1451, Braak I/II AV-1451 negatively predicted entorhinal cortical thickness, which resulted in a significant mediation. Numerical values are regression coefficients $(\beta)$ from models controlling for age, sex, and education. See text for more details. ${ }^{*} p<0.05$.

evidence supports the view that this increased MTL activity is detrimental. Because neural activity is associated with $\mathrm{A} \beta$ deposition (Cirrito et al., 2005; Bero et al., 2011), it is possible that this increased hippocampal activation is driving neural activity in other cortical regions, such as the retrosplenial cortex and precuneus, which are highly connected to the hippocampus and prone to $\mathrm{A} \beta$ deposition. Furthermore, some have suggested a component of excitotoxic damage in the $\mathrm{AD}$ pathophysiological cascade (Hynd et al., 2004; Ong et al., 2013) and the observed increased activation may be related to this process, to which the hippocampus is uniquely susceptible. This idea is supported by recent evidence linking increased hippocampal activation and atrophy in $\mathrm{AD}$-signature regions in cognitively normal older adults and patients with MCI (Putcha et al., 2011).

The current findings build on past studies by including measures of tau pathology along with A $\beta$. Decades of neuropathological investigation and recent clinical data support a model in which tau accumulation becomes ubiquitous in the MTL/entorhinal cortex in normal older adults, spreads to limbic regions and neocortex with the deposition of $\mathrm{A} \beta$, and strongly parallels cognition (Johnson et al., 2016; Cho et al., 2016; Ossenkoppele et al., 2016; Schöll et al., 2016; Schwarz et al., 2016). Relationships between tau deposition and hippocampal function appear reasonable in light of its topographical localization, along with evidence of its association with impaired memory (Schöll et al., 2016). For example, tau-related neurodegeneration (Spires- 
Jones and Hyman, 2014) and the resulting disconnection of entorhinal cortex from the hippocampus may potentiate the recurrent auto-associative fibers within the hippocampal circuitry that lead to pattern completion. In addition, there is strong evidence that tau accumulation is integral to producing aberrant neural activity in the presence of $A \beta$ (Roberson et al., 2011). This process may be exacerbated by an age-related reduction in hippocampal inhibitory interneurons (Vela et al., 2003; Stanley and Shetty, 2004), shifting the balance of excitation and inhibition within hippocampal subfields and leading to further aberrant activity.

\section{Experimental limitations}

There are limitations to the current study. A liberal cluster threshold was used for all task-related activation analyses, which could allow for false positives (Eklund et al., 2016). We feel that this concern is mitigated by the fact that our major findings reflect associations between activation and other biological variables. For example, the specific regional localization of activation within the MTL is not crucial, but rather we found that molecular pathology is associated with different aspects of a larger hippocampal memory network. Previous studies implementing the same task have examined only dentate gyrus and CA3 subfield function (Bakker et al., 2008; Yassa et al., 2011; Bakker et al., 2012); therefore, they use hybrid functional/structural ROIs, which are generated by masking thresholded $F$ statistics $(p<$ $0.05-0.07, k=10-100$ voxels) with hippocampal subfield ROIs. Their use of liberal thresholds suggests that the effects associated with this paradigm are small and may not be fully captured by strict cluster correction. However, we tried to address false positives by restricting voxelwise analyses to the hippocampus, entorhinal, perirhinal, and parahippocampal cortices. By doing so, we drastically limit the number of voxels and enhance signal-tonoise. We also acknowledge that our definition of the lure discrimination index may not reflect explicit pattern separation by including lure stimuli called new. Although a response of similar or new both reflect correct responses (because a response of new could result from judging lure stimuli to be dissimilar), it is also possible that a new response indicates inadequate encoding of the paired stimulus. We chose to include these responses to increase the number of trials associated with the measure; therefore, the measure may better reflect a failure of pattern completion. In addition, not all results could be corrected for multiple comparisons using Bonferroni correction. Specifically, relationships between individual measures of task-related activation and $\mathrm{AD}$ pathology would be nullified. Nevertheless, the association between $\mathrm{A} \beta$ and reduced deactivation replicates previous reports and the task-related activation associations with behavior and brain structure suggests their biological relevance. Finally, both PET tracers have limitations. PIB binds only to aggregated fibrillar forms of $\mathrm{A} \beta$, neglecting the pathological soluble forms. Previous work demonstrates that soluble and fibrillar forms of $A \beta$ may exist in equilibrium (Cirrito et al., 2003). However, because we have no measure of soluble $A \beta$, it is possible that our results underestimate the strength of relationships with $\mathrm{A} \beta$. Off-target binding of AV-1451 in the choroid plexus also poses a problem when quantifying hippocampal tau, but this problem was addressed through partial volume correction.

\section{Conclusions}

In summary, our results suggest that tau and $\mathrm{A} \beta$ are associated with aberrant activity within the MTL during memory encoding. Given the nature of $\mathrm{AD}$ pathology and the onset of its accumula- tion, longitudinal studies across the lifespan need to be performed to fully understand the influence of pathology on agerelated memory decline. However, these results indicate that both $\mathrm{A} \beta$ and tau play different but complementary roles in increasing neural activity during memory encoding, specifically in a manner that appears to be behaviorally detrimental and associated with structural brain change. These findings broaden the concept of cognitive aging to include evidence of $\mathrm{AD}$-related protein aggregation as an underlying mechanism of age-related memory impairment.

\section{References}

Arriagada PV, Growdon JH, Hedley-Whyte ET, Hyman BT (1992) Neurofibrillary tangles but not senile plaques parallel duration and severity of Alzheimer's disease. Neurology 42:631-639. CrossRef Medline

Bakker A, Kirwan CB, Miller M, Stark CE (2008) Pattern separation in the human hippocampal CA3 and dentate gyrus. Science 319:1640-1642. CrossRef Medline

Bakker A, Krauss GL, Albert MS, Speck CL, Jones LR, Stark CE, Yassa MA, Bassett SS, Shelton AL, Gallagher M (2012) Reduction of hippocampal hyperactivity improves cognition in amnestic mild cognitive impairment. Neuron 74:467-474. CrossRef Medline

Bennett DA, Schneider JA, Arvanitakis Z, Kelly JF, Aggarwal NT, Shah RC, Wilson RS (2006) Neuropathology of older persons without cognitive impairment from two community-based studies. Neurology 66:18371844. CrossRef Medline

Bennett IJ, Huffman DJ, Stark CE (2015) Limbic tract integrity contributes to pattern separation performance across the lifespan. Cereb Cortex 25: 2988-2999. CrossRef Medline

Bero AW, Yan P, Roh JH, Cirrito JR, Stewart FR, Raichle ME, Lee JM, Holtzman DM (2011) Neuronal activity regulates the regional vulnerability to amyloid- $\beta$ deposition. Nat Neurosci 14:750-756. CrossRef Medline

Braak H, Braak E (1991) Neuropathological stageing of Alzheimer-related changes. Acta Neuropathol 82:239-259. CrossRef Medline

Braak H, Braak E (1997) Frequency of stages of Alzheimer-related lesions in different age categories. Neurobiol Aging 18:351-357. CrossRef Medline

Busche MA, Eichhoff G, Adelsberger H, Abramowski D, Wiederhold KH, Haass C, Staufenbiel M, Konnerth A, Garaschuk O (2008) Clusters of hyperactive neurons near amyloid plaques in a mouse model of Alzheimer's disease. Science 321:1686-1689. CrossRef Medline

Cabeza R, Daselaar SM, Dolcos F, Prince SE, Budde M, Nyberg L (2004) Task-independent and task-specific age effects on brain activity during working memory, visual attention and episodic retrieval. Cereb Cortex 14:364-375. CrossRef Medline

Chabrier MA, Blurton-Jones M, Agazaryan AA, Nerhus JL, Martinez-Coria $\mathrm{H}$, LaFerla FM (2012) Soluble A $\beta$ promotes wild-type tau pathology in vivo. J Neurosci 32:17345-17350. CrossRef Medline

Cho H, Choi JY, Hwang MS, Kim YJ, Lee HM, Lee HS, Lee JH, Ryu YH, Lee MS, Lyoo CH (2016) In vivo cortical spreading pattern of tau and amyloid in the Alzheimer disease spectrum. Ann Neurol 80:247-258. CrossRef Medline

Cirrito JR, May PC, O’Dell MA, Taylor JW, Parsadanian M, Cramer JW, Audia JE, Nissen JS, Bales KR, Paul SM, DeMattos RB, Holtzman DM (2003) In vivo assessment of brain interstitial fluid with microdialysis reveals plaque-associated changes in amyloid-beta metabolism and halflife. J Neurosci 23:8844-8853. Medline

Cirrito JR, Yamada KA, Finn MB, Sloviter RS, Bales KR, May PC, Schoepp DD, Paul SM, Mennerick S, Holtzman DM (2005) Synaptic activity regulates interstitial fluid amyloid- $\beta$ levels in vivo. Neuron 48:913-922. CrossRef Medline

Crary JF, et al. (2014) Primary age-related tauopathy (PART): a common pathology associated with human aging. Acta Neuropathol 128:755-766. CrossRef Medline

Dale AM, Fischl B, Sereno MI (1999) Cortical surface-based analysis. I. Segmentation and surface reconstruction. Neuroimage 9:179-194. CrossRef Medline

Dennis NA, Hayes SM, Prince SE, Madden DJ, Huettel SA, Cabeza R (2008) Effects of aging on the neural correlates of successful item and source memory encoding. J Exp Psychol Learn Mem Cogn 34:791-808. CrossRef Medline

Duverne S, Motamedinia S, Rugg MD (2009) The relationship between ag- 
ing, performance, and the neural correlates of successful memory encoding. Cereb Cortex 19:733-744. CrossRef Medline

Duvernoy HM (2005) The human hippocampus. Berlin: Springer.

Eklund A, Nichols TE, Knutsson H (2016) Cluster failure: why fMRI inferences for spatial extent have inflated false-positive rates. Proc Natl Acad Sci U S A 113:7900-7905. CrossRef Medline

Elman JA, Oh H, Madison CM, Baker SL, Vogel JW, Marks SM, Crowley S, O'Neil JP, Jagust WJ (2014) Neural compensation in older people with brain amyloid- $\beta$ deposition. Nat Neurosci 17:1316-1318. CrossRef Medline

Fischl B, Liu A, Dale AM (2001) Automated manifold surgery: constructing geometrically accurate and topologically correct models of the human cerebral cortex. IEEE Trans Med Imaging 20:70-80. CrossRef Medline

Fischl B, Salat DH, Busa E, Albert M, Dieterich M, Haselgrove C, van der Kouwe A, Killiany R, Kennedy D, Klaveness S, Montillo A, Makris N, Rosen B, Dale AM (2002) Whole brain segmentation: automated labeling of neuroanatomical structures in the human brain. Neuron 33:341355. CrossRef Medline

Fonov VS, Evans AC, McKinstry RC, Almli CR, Collins DL (2009) Unbiased nonlinear average age-appropriate brain templates from birth to adulthood. Hum Brain Mapp 47:S102.

Hedden T, Gabrieli JD (2004) Insights into the ageing mind: a view from cognitive neuroscience. Nat Rev Neurosci 5:87-96. Medline

Huijbers W, Mormino EC, Wigman SE, Ward AM, Vannini P, McLaren DG, Becker JA, Schultz AP, Hedden T, Johnson KA, Sperling RA (2014) Amyloid deposition is linked to aberrant entorhinal activity among cognitively normal older adults. J Neurosci 34:5200-5210. CrossRef Medline

Huijbers W, Mormino EC, Schultz AP, Wigman S, Ward AM, Larvie M, Amariglio RE, Marshall GA, Rentz DM, Johnson KA, Sperling RA (2015) Amyloid- $\beta$ deposition in mild cognitive impairment is associated with increased hippocampal activity, atrophy and clinical progression. Brain 138:1023-1035. CrossRef Medline

Hynd MR, Scott HL, Dodd PR (2004) Glutamate-mediated excitotoxicity and neurodegeneration in Alzheimer's disease. Neurochem Int 45:583595. CrossRef Medline

Insausti R, Juottonen K, Soininen H, Insausti AM, Partanen K, Vainio P, Laakso MP, Pitkänen A (1998) MR volumetric analysis of the human entorhinal, perirhinal, and temporopolar cortices. AJNR Am J Neuroradiol 19:659-671. Medline

Jernigan TL, Archibald SL, Berhow MT, Sowell ER, Foster DS, Hesselink JR (1991) Cerebral structure on MRI, part I: localization of age-related changes. Biol Psychiatry 29:55-67. Medline

Johnson KA, et al. (2016) Tau positron emission tomographic imaging in aging and early Alzheimer disease. Ann Neurol 79:110-119. CrossRef Medline

Kennedy KM, Rodrigue KM, Devous MD Sr, Hebrank AC, Bischof GN, Park DC (2012) Effects of beta-amyloid accumulation on neural function during encoding across the adult lifespan. Neuroimage 62:1-8. CrossRef Medline

Laakso MP, Partanen K, Riekkinen P, Lehtovirta M, Helkala EL, Hallikainen M, Hanninen T, Vainio P, Soininen H (1996) Hippocampal volumes in Alzheimer"s disease, Parkinson"s disease with and without dementia, and in vascular dementia: an MRI study. Neurology 46:678-681. CrossRef Medline

Logan J (2000) Graphical analysis of PET data applied to reversible and irreversible tracers. Nucl Med Biol 27:661-670. CrossRef Medline

Marr D (1971) Simple memory: a theory for archicortex. Philos Trans R Soc Lond B Biol Sci 262:23-81. CrossRef Medline

Mathalon DH, Sullivan EV, Rawles JM, Pfefferbaum A (1993) Correction for head size in brain-imaging measurements. Psychiatry Res Neuroimaging 50:121-139. CrossRef Medline

Mattson MP, Cheng B, Davis D, Bryant K, Lieberburg I, Rydel RE (1992) $\beta$-Amyloid peptides destabilize calcium homeostasis and render human cortical neurons vulnerable to excitotoxicity. J Neurosci 12:376-389. Medline

Miller SL, Celone K, DePeau K, Diamond E, Dickerson BC, Rentz D, Pihlajamäki M, Sperling RA (2008) Age-related memory impairment associated with loss of parietal deactivation but preserved hippocampal activation. Proc Natl Acad Sci U S A 105:2181-2186. CrossRef Medline

Mormino EC, Smiljic A, Hayenga AO, Onami SH, Greicius MD, Rabinovici GD, Janabi M, Baker SL, Yen IV, Madison CM, Miller BL, Jagust WJ (2011) Relationships between $\beta$-amyloid and functional connectivity in different components of the default mode network in aging. Cereb Cortex 21:2399-2407. CrossRef Medline

Mormino EC, Brandel MG, Madison CM, Marks S, Baker SL, Jagust WJ (2012) $A \beta$ deposition in aging is associated with increases in brain activation during successful memory encoding. Cereb Cortex 22:1813-1823. CrossRef Medline

Ong WY, Tanaka K, Dawe GS, Ittner LM, Farooqui AA (2013) Slow excitotoxicity in Alzheimer's disease. J Alzheimers Dis 35:643-668. CrossRef Medline

O’Reilly RC, Norman KA (2002) Hippocampal and neocortical contributions to memory: advances in the complementary learning systems framework. Trends Cogn Sci 6:505-510. CrossRef Medline

Ossenkoppele R, Schonhaut DR, Schöll M, Lockhart SN, Ayakta N, Baker SL, O’Neil JP, Janabi M, Lazaris A, Cantwell A, Vogel J, Santos M, Miller ZA, Bettcher BM, Vossel KA, Kramer JH, Gorno-Tempini ML, Miller BL, Jagust WJ, Rabinovici GD (2016) Tau PET patterns mirror clinical and neuroanatomical variability in Alzheimer's disease. Brain 139:1551-1567. CrossRef Medline

Palop JJ, Chin J, Roberson ED, Wang J, Thwin MT, Bien-Ly N, Yoo J, Ho KO, Yu GQ, Kreitzer A, Finkbeiner S, Noebels JL, Mucke L (2007) Aberrant excitatory neuronal activity and compensatory remodeling of inhibitory hippocampal circuits in mouse models of Alzheimer's disease. Neuron 55:697-711. CrossRef Medline

Price JC, Klunk WE, Lopresti BJ, Lu X, Hoge JA, Ziolko SK, Holt DP, Meltzer CC, DeKosky ST, Mathis CA (2005) Kinetic modeling of amyloid binding in humans using PET imaging and Pittsburgh Compound-B. J Cereb Blood Flow Metab 25:1528-1547. CrossRef Medline

Price JL, Morris JC (1999) Tangles and plaques in nondemented aging and "preclinical" Alzheimer's disease. Ann Neurol 45:358-368. CrossRef Medline

Pruessner JC, Collins DL, Pruessner M, Evans AC (2001) Age and gender predict volume decline in the anterior and posterior hippocampus in early adulthood. J Neurosci 21:194-200. Medline

Pruessner JC, Köhler S, Crane J, Pruessner M, Lord C, Byrne A, Kabani N, Collins DL, Evans AC (2002) Volumetry of temporopolar, perirhinal, entorhinal and parahippocampal cortex from high-resolution MR images: considering the variability of the collateral sulcus. Cereb Cortex 12:1342-1353. CrossRef Medline

Putcha D, Brickhouse M, O'Keefe K, Sullivan C, Rentz D, Marshall G, Dickerson B, Sperling R (2011) Hippocampal hyperactivation associated with cortical thinning in Alzheimer's disease signature regions in nondemented elderly adults. J Neurosci 31:17680-17688. CrossRef Medline

Raz N, Rodrigue KM, Head D, Kennedy KM, Acker JD (2004) Differential aging of the medial temporal lobe. Neurology 62:433-438. CrossRef Medline

Roberson ED, Halabisky B, Yoo JW, Yao J, Chin J, Yan F, Wu T, Hamto P, Devidze N, Yu GQ, Palop JJ, Noebels JL, Mucke L (2011) Amyloid- $\beta$ / Fyn-induced synaptic, network, and cognitive impairments depend on tau levels in multiple mouse models of Alzheimer's disease. J Neurosci 31:700-711. CrossRef Medline

Rousset OG, Ma Y, Evans AC (1998) Correction for partial volume effects in PET: principle and validation. J Nucl Med 39:904-911. Medline

Scheltens PH (2001) Structural neuroimaging of Alzheimer's disease and other dementias. Aging (Milano) 13:203-209. CrossRef Medline

Schöll M, Lockhart SN, Schonhaut DR, O’Neil JP, Janabi M, Ossenkoppele R, Baker SL, Vogel JW, Faria J, Schwimmer HD, Rabinovici GD, Jagust WJ (2016) PET imaging of tau deposition in the aging human brain. Neuron 89:971-982. CrossRef Medline

Schwarz AJ, Yu P, Miller BB, Shcherbinin S, Dickson J, Navitsky M, Joshi AD, Devous MD Sr, Mintun MS (2016) Regional profiles of the candidate tau PET ligand 18F-AV-1451 recapitulate key features of Braak histopathological stages. Brain 139:1539-1550. CrossRef Medline

Ségonne F, Dale AM, Busa E, Glessner M, Salat D, Hahn HK, Fischl B (2004) A hybrid approach to the skull stripping problem in MRI. Neuroimage 22:1060-1075. CrossRef Medline

Small SA, Stern Y, Tang M, Mayeux R (1999) Selective decline in memory function among healthy elderly. Neurology 52:1392-1396. CrossRef Medline

Sperling RA, Bates JF, Chua EF, Cocchiarella AJ, Rentz DM, Rosen BR, Schacter DL, Albert MS (2003) fMRI studies of associative encoding in young and elderly controls and mild Alzheimer's disease. J Neurol Neurosurg Psychiatry 74:44-50. CrossRef Medline 
Sperling RA, Laviolette PS, O'Keefe K, O’Brien J, Rentz DM, Pihlajamaki M, Marshall G, Hyman BT, Selkoe DJ, Hedden T, Buckner RL, Becker JA, Johnson KA (2009) Amyloid deposition is associated with impaired default network function in older persons without dementia. Neuron 63: 178-188. CrossRef Medline

Spires-Jones TL, Hyman BT (2014) The intersection of amyloid beta and tau at synapses in Alzheimer's disease. Neuron 82:756-771. CrossRef Medline

Stanley DP, Shetty AK (2004) Aging in the rat hippocampus is associated with widespread reductions in the number of glutamate decarboxylase-67 positive interneurons but not interneuron degeneration. J Neurochem 89:204-216. CrossRef Medline

Thal DR, Rüb U, Orantes M, Braak H (2002) Phases of A $\beta$-deposition in the human brain and its relevance for the development of AD. Neurology 58:1791-1800. CrossRef Medline

Treves A, Rolls ET (1994) Computational analysis of the role of the hippocampus in memory. Hippocampus 4:374-391. CrossRef Medline

van Rossum IA, Visser PJ, Knol DL, van der Flier WM, Teunissen CE, Barkhof F, Blankenstein MA, Scheltens P (2012) Injury markers but not amyloid markers are associated with rapid progression from mild cognitive impairment to dementia in Alzheimer's disease. J Alzheimers Dis 29:319327. CrossRef Medline

Vannini P, Hedden T, Becker JA, Sullivan C, Putcha D, Rentz D, Johnson KA, Sperling RA (2012) Age and amyloid-related alterations in default net- work habituation to stimulus repetition. Neurobiol Aging 33:1237-1252. CrossRef Medline

Vela J, Gutierrez A, Vitorica J, Ruano D (2003) Rat hippocampal GABAergic molecular markers are differentially affected by ageing. J Neurochem 85:368-377. CrossRef Medline

Villeneuve S, et al. (2015) Existing Pittsburgh Compound-B positron emission tomography thresholds are too high: statistical and pathological evaluation. Brain 138:2020-2033. CrossRef Medline

Xia CF, Arteaga J, Chen G, Gangadharmath U, Gomez LF, Kasi D, Lam C, Liang Q, Liu C, Mocharla VP, Mu F, Sinha A, Su H, Szardenings AK, Walsh JC, Wang E, Yu C, Zhang W, Zhao T, Kolb HC (2013) [18F]T807, a novel tau positron emission tomography imaging agent for Alzheimer's disease. Alzheimers Dement 9:666-676. CrossRef Medline

Yassa MA, Muftuler LT, Stark CE (2010a) Ultrahigh-resolution microstructural diffusion tensor imaging reveals perforant path degradation in aged humans in vivo. Proc Natl Acad Sci U S A 107:12687-12691. CrossRef Medline

Yassa MA, Stark SM, Bakker A, Albert MS, Gallagher M, Stark CE (2010b) High-resolution structural and functional MRI of hippocampal CA3 and dentate gyrus in patients with amnestic mild cognitive impairment. Neuroimage 51:1242-1252. CrossRef Medline

Yassa MA, Lacy JW, Stark SM, Albert MS, Gallagher M, Stark CE (2011) Pattern separation deficits associated with increased hippocampal CA3 and dentate gyrus activity in nondemented older adults. Hippocampus 21:968-979. CrossRef Medline 